this reason and for the fact that his enthusiasm for symmetry physics is one of the expected pleasures of such occasions.

Non-compact groups are the mathematically opulent approach to elementary particles. A more mathematically economical, if physically rather opaque, line of attack is afforded by the use of quark models. Indeed, so economical is this latter approach that it has been noticeably success. ful in getting many of the $S U(6)$ results without actually assuming $S U(6)$. An investigation of this was reported by Lipkin. Characteristically he finds an interesting new sub-group as the cause.

An elusive particle (if it exists at all) is the magnetic monopole suggested by Dirac in 1931. As he pointed out, it is theoretically desirable since it leads to the otherwise unexplained quantization of electric charge. Schwinger gave a new account of the theory which leads to a different, more restrictive, quantization condition.

The final arbiters of all symmetry schemes are the experimentalists, whose findings can sometimes confirm and often destroy a theoretically elegant possibility. Excellent surveys of the present situation were given by Samios and Frisch. However, occasionally the theorists can get their revenge. Another experimentalist gave a talk on an experiment which he was planning, but a very quick-witted theorist pointed out in a spontaneous comment that the effect sought was identical with, and thus not capable of being disentangled from, another interaction also present. As someone else pointed out, the saving as a result of this observation more than paid for the whole Conference.

\section{J. C. Polikinghorne}

\title{
EARTHING OF ELECTRICAL SYSTEMS
}

\begin{abstract}
$T$ HE safety and integrity of electrical power supply systems are almost universally dependent on some form of earthing which aims at limiting, under fault conditions, the potential difference between the general body of earth and certain parts of the system. The British Standards Institution has recently published a Code of Practice (CP 1013: 1965--Earthing) dealing with the subject*.

System earthing, as distinct from the earthing of electrical apparatus, began in the 1890's when the supply was utilized almost wholly for lighting and the need for equipment earthing on consumers' premises was relatively slight. Practice in the matter of earthing consumers' installations developed relatively slowly. While there is no mention of earthing in the first edition of the Institution of Electrical Engineer's Wiring Regulations issued in 1885, the third edition of 1897 recommends the earthing of the frames of dynamos and motors and of transformers. The eighth edition published in 1924 contains a substantial section dealing with consumers' installations and mentioning the provision of earth terminals.

Although the safety of electrical installations is a subject which has received much attention in recent years, it is probably not generally sufficiently realized that satisfactory protection by means of simple earthing, together with fuses or circuit breakers, becomes progressively

* The Council for Codes of Practice, British Standards Institution. British Standard Code of Practice, $C P$ 101.3: 1965-Earthing. Pp. 129. (London:
\end{abstract} British Standards Institution.) $30 s$, net. more difficult of achievement as the load taken by the consumer increases.

While, in general, the question of how an electrical system shall be earthed is governed by legislation, the regulations are so worded as to permit any type of earthing provided that it is as safe as is practicable and that it is unlikely to interfere with telecommunication.

The new code of practice deals comprehensively with general considerations and with specific practices relating to the earthing of supply systems and of consumers' installations. There are six main sections, two of which, entitled "General" and "Design Considerations", deal with principles and practice concerning power stations, transmission and distribution systems, consumers' premises, traction and lightning protection. Sections 3, 4 and 5 deal respectively with the temporary safety earthing of high-voltage apparatus or mains, inspection and testing and maintenance. Section 6, which completes the work and is entitled "Miscellaneous", is concerned mainly with a number of specific legislative provisions.

Opening with a statement of scope, followed by a list of definitions, the subject is developed clearly and concisely and with an adequate amount of explanatory material. The Code constitutes an admirably comprehensive guide to earthing practice which will be a work of day-to-day reference for supply engineers, electrical contractors, maintenance engineers and, indeed, for all who have responsibility for electrical installations.

JAMES GREIG

\section{VOLCANOLOGY RESEARCH IN NEW ZEALAND}

$I_{\text {and }}^{\mathrm{N}}$ 1963, the Royal Society of New Zealand and the New Zealand Geological Survey (Department of Scientific and Industrial Research) invited the International Association of Volcanology to hold its 1965 symposium in New Zealand, to mark the centenary of the New Zealand Geological Survey. This symposium, held during November 22-December 3 at Auckland, Rotorua, Taupo and Wellington, was attended by more than one hundred delegates from twenty-three countries. The two main subjects were acid volcanism (including ignimbrites) and geothermal resources.

The problem of the genesis of acid volcanic rocks is particularly acute in an area such as the central volcanic zone of the North Island of New Zealand, where the volume of these highly silicic rocks greatly exceeds that of basic and intermediate types, and where individual eruptive units of acid rock are of such enormous volume. The problem hinges on whether this acid magma was produced by the large-scale fusion of crustal material or is a fractionation product of basic magma, itself generated originally within the upper mantle. A further possibility is that the acid magma may even come directly from the mantle.

In New Zealand, the basement which is believed to underlie the volcanic rocks includes a great thickness of Mesozoic to Tertiary greywackes. The chemical composition of these greywackes is such that their partial fusion could produce a melt similar in composition to the observed acid volcanic rocks. This origin is at present favoured by Now Zealand geologists; basic and intermediate volcanic material is not sufficiently abundant to be quantitatively acceptable as a parental magma. Geochemical studies which have a bearing on this problem were discussed 